\title{
Association between tumor necrosis factor alpha and obstructive sleep apnea in adults: a meta-analysis update
}

\author{
Yuan Cao ${ }^{1 \dagger}$, Yali Song ${ }^{2 \dagger}$, Pu Ning ${ }^{1}$, Liyu Zhang ${ }^{3}$, Shuang Wu${ }^{4}$, Juan Quan ${ }^{5}$ and Qiao Li $^{4^{*}}$ (D)
}

\begin{abstract}
Background: Tumor necrosis factor-a (TNF-a) has been reported to play a part in the development of obstructive sleep apnea (OSA) and its complications. However, the relationship between TNF-a and OSA still remains inconclusive. We aimed to systematically review and synthesize studies published to date on association between the two in adults.

Methods: We searched for English-language articles containing original human data from case-control study studies in adults $\geq 18$ years of age. The selection criteria were set according to the PICOS framework. Articles were independently reviewed by three investigators. Data regarding demographics, clinical characteristics, and TNF-a levels were obtained. A random-effects model was applied to evaluate the overall effect sizes by calculating standard mean difference (SMD) and its 95\% confidence intervals (C/s).

Results: Of 393 identified abstracts, 50 articles (3503 OSA patients and 3379 health controls) were ultimately included in this meta-analysis. The results indicated that the TNF-a level in patients with OSA was $1.77\left(95 \% \mathrm{Cl}, 1.37\right.$ to $2.17, P^{2}=$ $97.8 \%, P<0.0001)$ times higher than in the control group. Subgroup analyses showed a positive correlation between the level of TNF-a and OSA severity. According to meta-regression, we noted that aging significantly predicted an increased effect size of TNF-a level in OSA patients $(P<0.007)$.

Conclusion: This study identified a significant association between OSA and elevated TNF-a level in adults. Meanwhile, TNF-a levels were consistently correlated with severity of OSA, which indicated it might be a promising biomarker for the development of OSA. However, well-designed, large-scale, case-control cohorts are needed to better understand the relationship of TNF-a in the context of adult OSA.
\end{abstract}

Keywords: Obstructive sleep apnea, Meta-analysis, Tumor necrosis factor-a

\section{Background}

Obstructive sleep apnea (OSA) is a common chronic respiratory disease, and presented a high prevalence in the general population. It estimated that the overall prevalence of symptomatic OSA is 15 to $50 \%$ in general population, and the rates are still increasing [1]. OSA is

\footnotetext{
* Correspondence: liqiao@csu.edu.cn

${ }^{+}$Yuan Cao and Yali Song contributed equally to this work.

${ }^{4}$ Clinical Laboratory, The Affiliated Children Hospital of Xi'an Jiaotong University, Xi'an, Shaanxi, China

Full list of author information is available at the end of the article
}

characterized by repetitive collapse of the upper airway during sleep, which leads to intermittent hypoxia and arousals during sleep, moreover, it increases the risks of complications of cardiovascular, neurocognitive disturbance, and metabolic morbidities [2, 3]. Furthermore, long-term hypoxia will increase the systemic inflammation of patients with OSA. With the accumulation of these increasing inflammatory cytokines and mediators, it will further contribute to the onset of OSA.

C C The Author(s). 2020 Open Access This article is licensed under a Creative Commons Attribution 4.0 International License, which permits use, sharing, adaptation, distribution and reproduction in any medium or format, as long as you give appropriate credit to the original author(s) and the source, provide a link to the Creative Commons licence, and indicate if changes were made. The images or other third party material in this article are included in the article's Creative Commons licence, unless indicated otherwise in a credit line to the material. If material is not included in the article's Creative Commons licence and your intended use is not permitted by statutory regulation or exceeds the permitted use, you will need to obtain permission directly from the copyright holder. To view a copy of this licence, visit http://creativecommons.org/licenses/by/4.0/ The Creative Commons Public Domain Dedication waiver (http://creativecommons.org/publicdomain/zero/1.0/) applies to the data made available in this article, unless otherwise stated in a credit line to the data. 
Tumor Necrosis Factor Alpha (TNF- $\alpha)$ is a proinflammatory cytokine which usually is secreted by mononuclear-macrophage, natural killer cells, and other immune cells $[4,5]$. It plays a crucial role in host defense and mediates the pathogenesis of a wide spectrum of disease processes such as cancers, infectious diseases, autoimmune diseases, cardiovascular diseases and atherosclerosis [5]. TNF- $\alpha$ has been implicated in the regulation of sleep by activating NF- $\mathrm{B}$ pathways, and leading to upregulate of adenosine A1 receptor, cyclooxygenase-2, and NO synthase, which thought to be involved in sleep regulation [6, 7]. And, TNF- $\alpha$ antagonist has proven to attenuate cognitive and behavioral disturbances, thus, ameliorate the progression of OSA $[8,9]$. Previous literatures had utilized the levels of TNF$\alpha$ in the blood or excretion of OSA patients as an evaluation indicator of occurrence and disease development, and usually increased compared with healthy subjects or decreased after treatment $[10,11]$. It was also mentioned that TNF- $\alpha$ could assess the degree of OSA. However, due to the range of nations, regions, severity in OSA patients, sample size, comorbidity of patients, specimens, and methods of detection varied among different studies, with the majority of studies lacking a uniform procedure, thus had less adequate statistical power to clarify the relationship between TNF- $\alpha$ and OSA.

To comprehensively understand TNF- $\alpha$ in OSA, we performed this meta-analysis in patients with OSA to evaluate whether the levels of TNF- $\alpha$ were higher than in healthy controls and, to identify the association between TNF- $\alpha$ and OSA in adults.

\section{Methods}

\section{Literature search}

We systematically searched four electronic databases (PubMed, Web of Science, EMBASE, and Cochrane library database CENTRAL) through September 2019. The search terms included ['Respiration Disorders, Sleep Apnea Syndromes' or 'obstructive Sleep Apnea' or 'chronic obstructive airway disease' or 'OSA' or 'OSAHS'] and ['Tumor necrosis factor-a' or 'Tumor necrosis factor alpha' or 'TNF- $\alpha$ '] and ('systemic inflammation' or 'biological markers'). Only articles published in English were included. We also went through the references of eligible studies and manually review articles to identify possible relevant publications.

\section{Study selection}

The PICOS (population, intervention, comparison, outcomes, and study design) framework was introduced as inclusion criteria. All articles had to meet certain criteria (see supplementary Table 1). OSA patients were diagnosed according to the clinical practice guideline from the American College of Physicians [12]. Studies eligible for the meta-analysis included those that measured the levels TNF- $\alpha$ in OSA or controls and in which the degrees of TNF- $\alpha$ should determine using $\mathrm{pg} / \mathrm{ml}$ or calculate to accordant unit.

The exclusion criteria include studies that included participants with a history or diagnosis of other respiratory, cardiovascular and endocrine diseases overlapping with OSA; pediatric or adolescent studies, patients who received nutritional support or undergoing therapy (medication, operation, continuous positive airway pressure); case reports or those articles lacking statistical data; articles without control group (articles with only case groups could be included in subgroup analysis).

\section{Data extraction}

Two authors (Yuan Cao and Qiao Li) independently screened the literature and extracted data to ensure that the screening core criteria and data gathering were consistent. If the opinions were different, further discussion was carried out or an additional person (Yali Song) was invited to participate in discussions until a consensus was reached. By designing a data extraction form and following items were drawn from the qualified articles: the first author, year of publication, nationality, sample size, gender, BMI, study design, levels of TNF- $\alpha$.

The quality of the included studies was evaluated according to the Newcastle-Ottawa Scale (NOS). Two authors independently performed the analyses, and consensus was reached on all decisions.

\section{Statistical analysis and data synthesis}

All data were entered into STATA, version 13.0 for meta-analysis. Data were presented as mean $\pm \mathrm{SD}$ to evaluate the relationships between TNF- $\alpha$ and OSA. If the data were presented as mean (95\% confidence interval), median (range), or median (interquartile), the formula from the published articles was used to convert the data and calculate SD $[13,14]$. The heterogeneity of the studies was measured using the $I^{2}$ statistic, with the level of significance set at $P<0.05$, and $I^{2}$ values of 25, 50, and $75 \%$ representing low, moderate, and high heterogeneity, respectively. Considering the probable heterogeneity of the studies, a random-effects model was performed in the meta-analysis following the approach of DerSimonian and Laird [15]. Likewise, a subgroup analysis was conducted to compare observed effects between OSA and controls, with $P<0.05$ denoting statistical significance. Publication bias was assessed by funnel plot and using Egger's test, and then conducted a trim and fill analysis was conducted, as well as a sensitivity analysis to adjust asymmetry of funnel plot to address the problem of publication bias. 


\section{Results}

\section{Characteristics of the individual studies}

Our database search initially revealed a total of 248 articles. After checked for duplication, 248 studies were included in our meta-analysis, in which, 145 articles need further screen. After reading the title and abstract of each article, 48 articles were excluded. The remaining 97 articles were screened by the inclusion and exclusion criteria. Finally, 50 articles reporting data from 3503 OSA patients and 3379 health controls were included in the meta-analysis (Fig. 1).

The studies were published from 1993 through March 2019. Of those, 25 studies were conducted in Asia, 18 in Europe, and 7 in America. Among all the studies, 14 concentrated on the severity of OSA, mild OSA was reported in 7 studies, mild to moderate was reported in 6 studies, moderate OSA was reported in 5 studies, moderate to severe OSA was reported in 13 studies, and severe OSA was reported in 5 studies.

The baseline characteristics and NOS scores of each study included in our meta-analysis are listed in Table 1 [10, 11, 16-64]. Forty-four studies scored more than 5 stars in NOS which suggested a high-quality study. The sample size, mean age, gender, mean BMI, and levels of
TNF- $\alpha$ of individuals in the studies are provided in Table 1.

\section{Meta-analysis and publication bias}

The level of TNF- $\alpha$ in OSA patients was 1.77 (95\%CI, 1.37 to $\left.2.17, I^{2}=97.8 \%, P<0.0001\right)$ times higher than in the control group when all the data from the 50 studies were combined with the random-effects model (Fig. 2). By applying a funnel plot and Egger's test, publication bias of the literature was evaluated, see Fig. 3a $(t=3.33$ and $P=$ $0.001)$. Heterogeneity was partially explained by small studies reporting a larger effect and various detection methods and specimens from each study (see subgroup analysis) may have contributed to it. Through omission of each of the included literature studies, results were less changed following sensitivity analysis (Fig. S1, and Table S1). The funnel plots were also adjusted using the trim and fill analysis, see Fig. 3b. By trimming 24 sets of data, the overall SMD (95\% CI) changed from 1.768 (1.367 to 2.169 ) to 1.721 (1.063 to 2.787 ), which suggesting little evidence of publication bias.

There were complications mentioned in some of the studies including obese, hypertension, and fatty liver

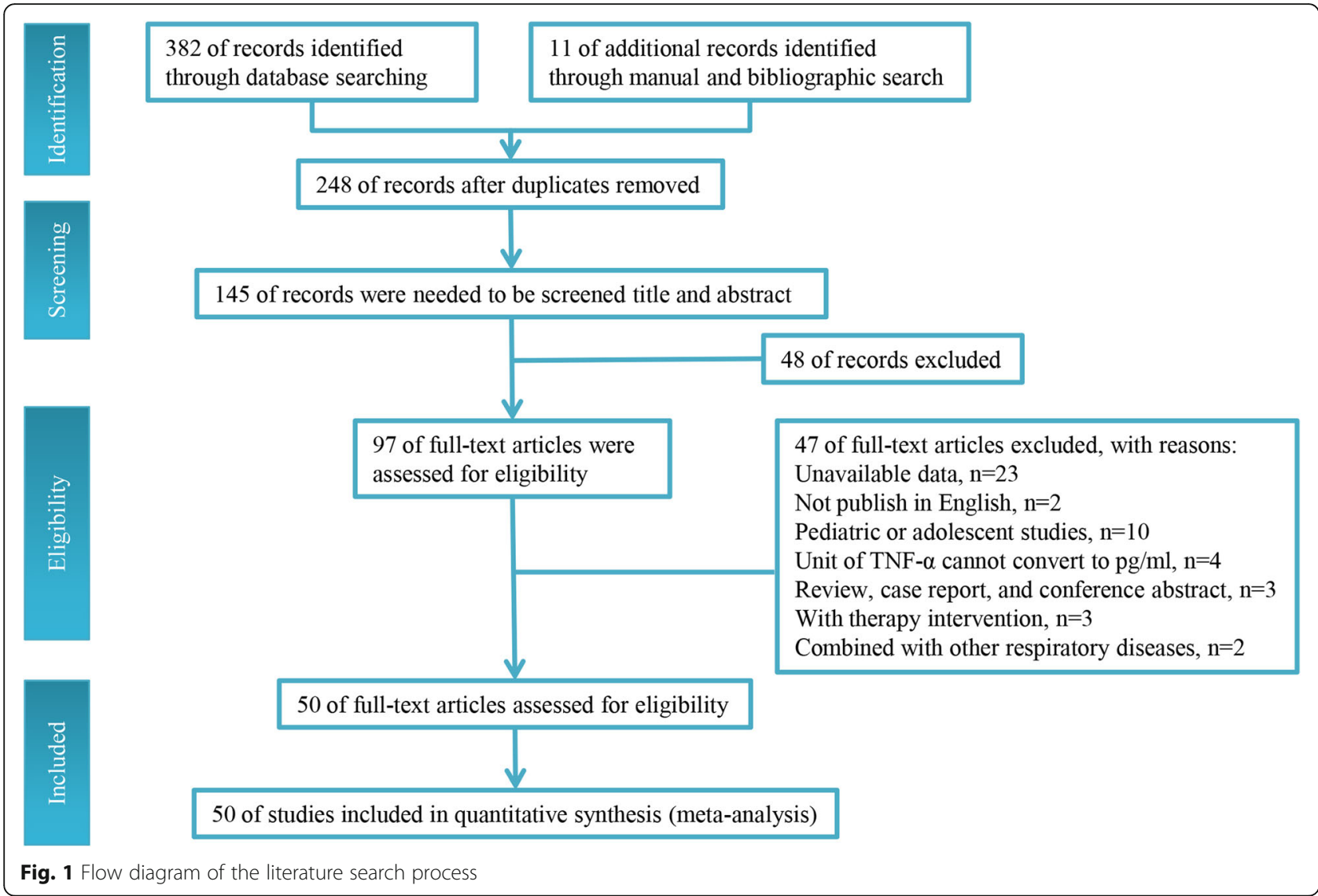




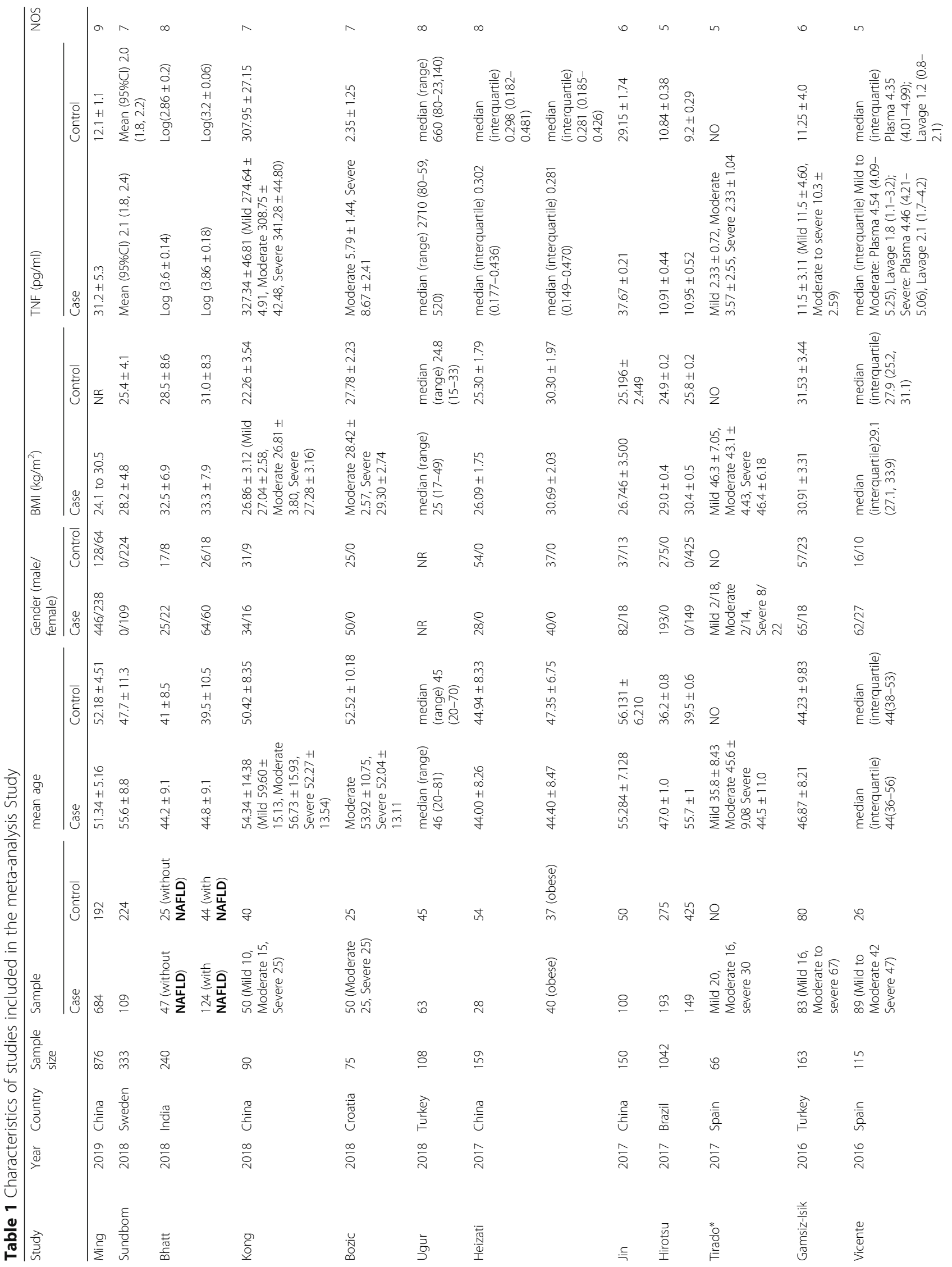




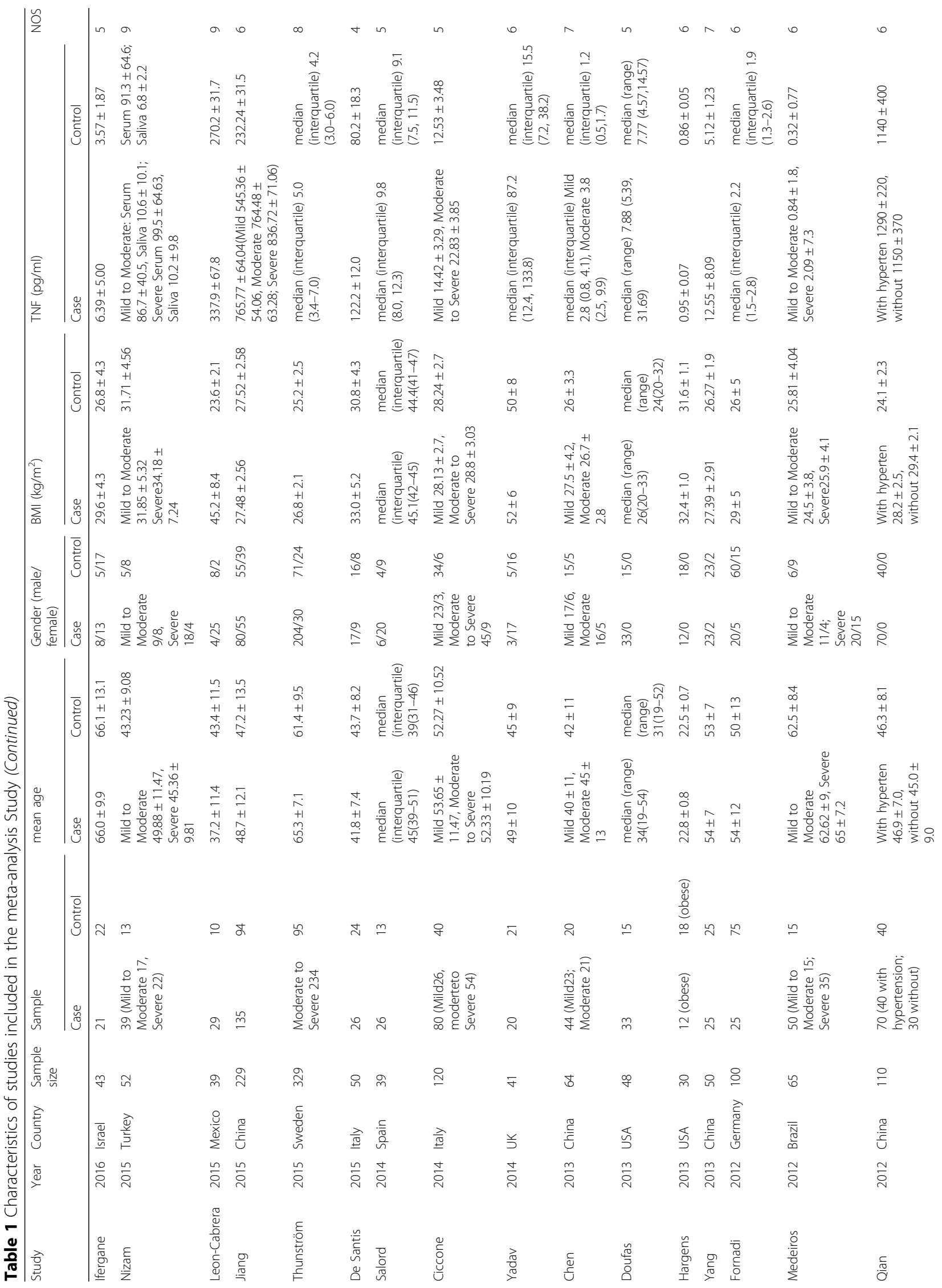




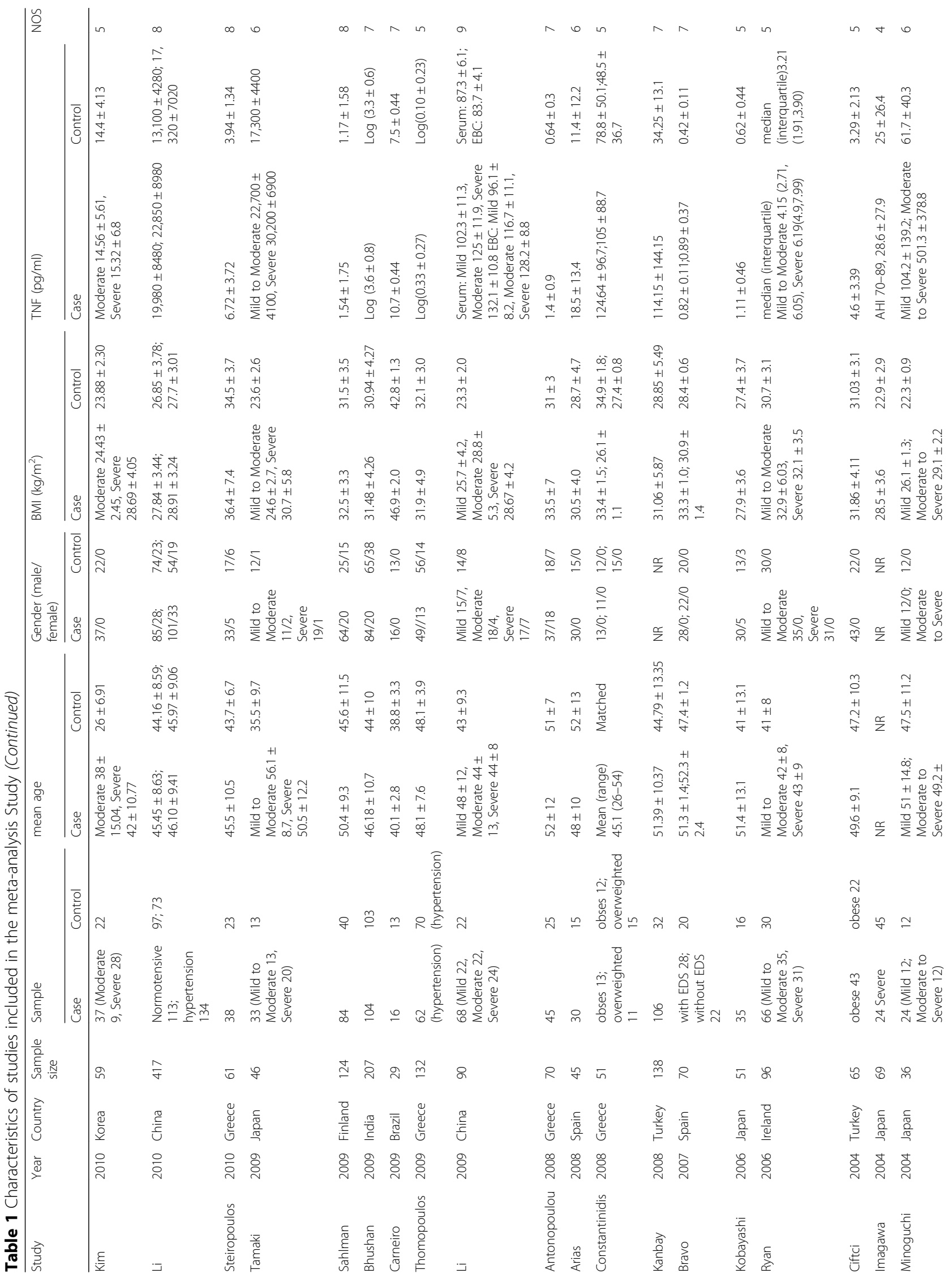




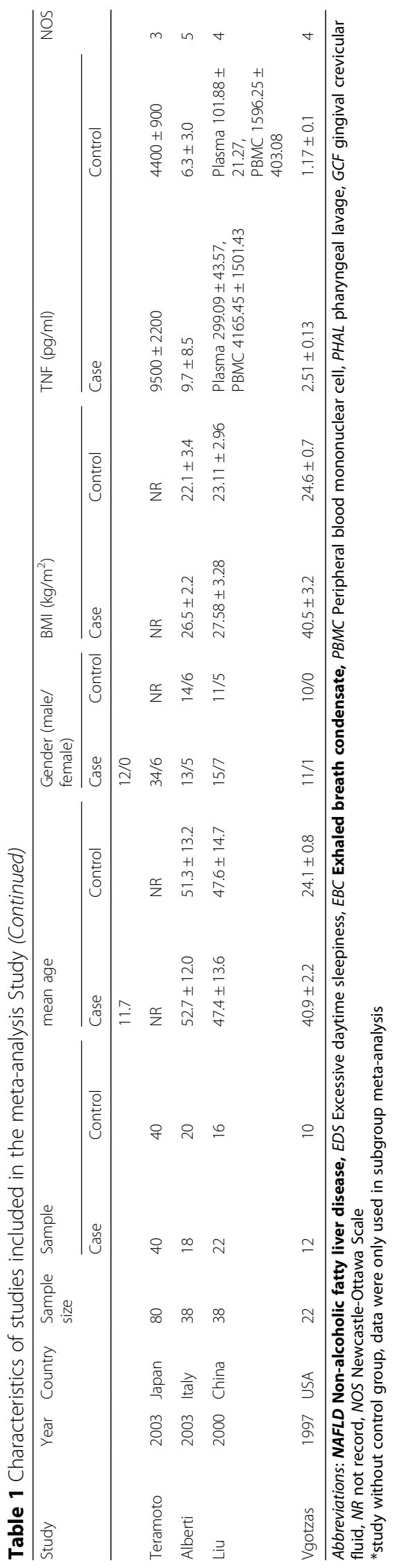




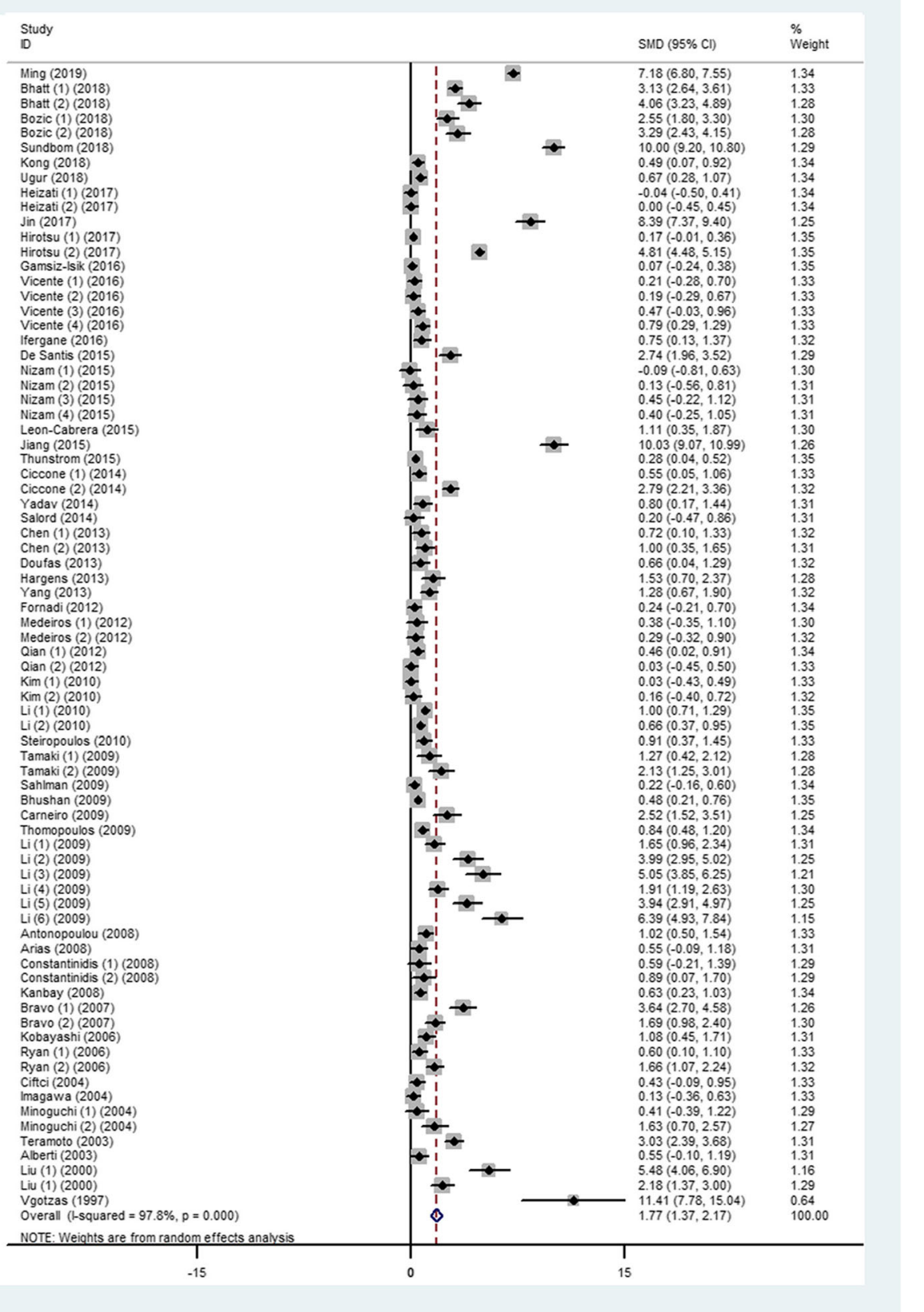

Fig. 2 Comparison of TNF-a level between OSA patients and controls in the included studies

disease. After removal of those articles, the heterogeneity was still significant (SMD 1.86, 95\%CI: 1.41 to $2.32, I^{2}=$ $98 \%, P<0.0001)$, see Fig. 4 .

\section{Subgroup analysis}

Based on the region of each study, the level of TNF- $\alpha$ of OSA patients was 2.56 , which was 1.41 times higher than the control group in developing and developed countries, individually $\left(I^{2}=98.7 \%, P<0.0001 ; I^{2}=95.5 \%, P<0.0001\right.$. Fig. S2). The TNF- $\alpha$ was still high in OSA when the individuals were divided into groups from three continents $(P<0.0001)$ : Asia: SMD 2.34, 95\%CI: 1.67 to 3.01; Europe: SMD 1.44, 95\%CI: 0.88 to 2.01; America: SMD 2.15, 95\%CI: 0.60 to 3.70 (Fig. S3). Fig. S4 demonstrates that gender did not influence the level of TNF- $\alpha$ in OSA $(P<0.0001)$ : males: SMD 1.22, 95\%CI: 0.80 to 1.64, and females: SMD 7.39, 95\%CI: 2.31 to 12.48. Seven specimens were used for testing the TNF- $\alpha$ level, among which, serum and plasma were commonly used, and the heterogeneity was significant in those two specimen (SMD 1.68, 95\%CI: 0.95 to 2.41, $P<0.0001$; SMD 1.92, 


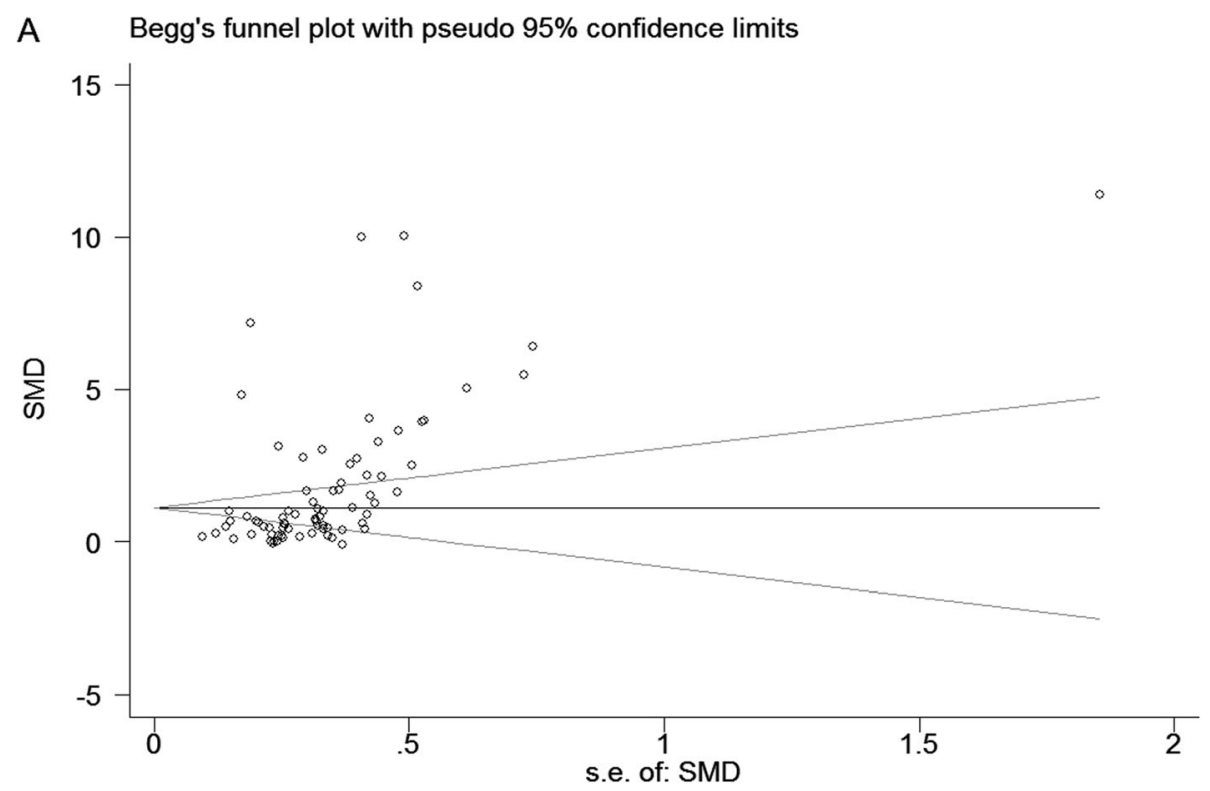

B Filled funnel plot with pseudo $95 \%$ confidence limits

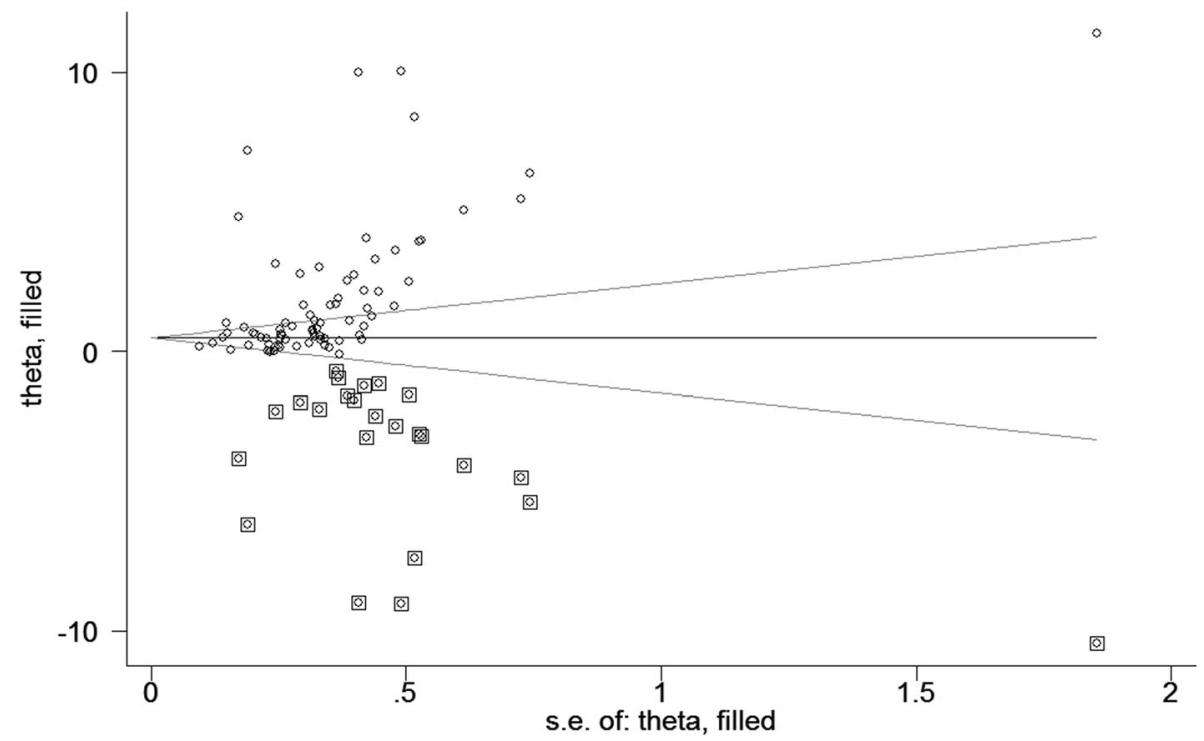

Fig. 3 a: A funnel plot analysis of publication bias; b: A funnel plot adjusted by the trim \& fill analysis

95\%CI: 1.30 to $2.53, P<0.0001)$. However, the TNF- $\alpha$ in the pharyngeal lavage (SMD 0.63, 95\%CI: 0.28 to $0.98, P=$ 0.370), saliva (SMD 0.46, 95\%CI: -0.05 to $0.96, P=0.907$ ), and the peripheral blood mononuclear cells (SMD 1.86, 95\%CI: 1.28 to $2.44, P=0.243$ ) of OSA had no more statistical significance than they did in counterparts of healthy controls (Fig. 5). Additionally, the TNF- $\alpha$ level in exhaled breath condensate OSA patients were still 3.22 times higher than in control individuals (Fig. 5). For most of the included studies, enzyme linked immunosorbent assay (ELISA) was used to measure the level of TNF- $\alpha$ (SMD 1.85, 95\%CI: 1.41 to $2.28, P<0.0001$ ), chemiluminescence analysis (CLIA) was used in three studies (SMD 4.37, 95\%CI: 0.58 to 8.16). The remaining two studies were administrated by electrochemiluminescence immunoassay (ECLIA) and polymerase chain reaction (PCR), separately (see Fig. S5).

Subgroup analysis for the severity of OSA is shown in Fig. 6. Other than the mild to moderate versus the severe group (SMD 0.42, 95\%CI: 0.12 to $0.73, P=0.014$ ), other subgroups all reached a statistical significance (Fig. 6).

\section{Meta-regression}

The meta-regression showed that an increase in age of OSA patients significantly predicted an increased effect 


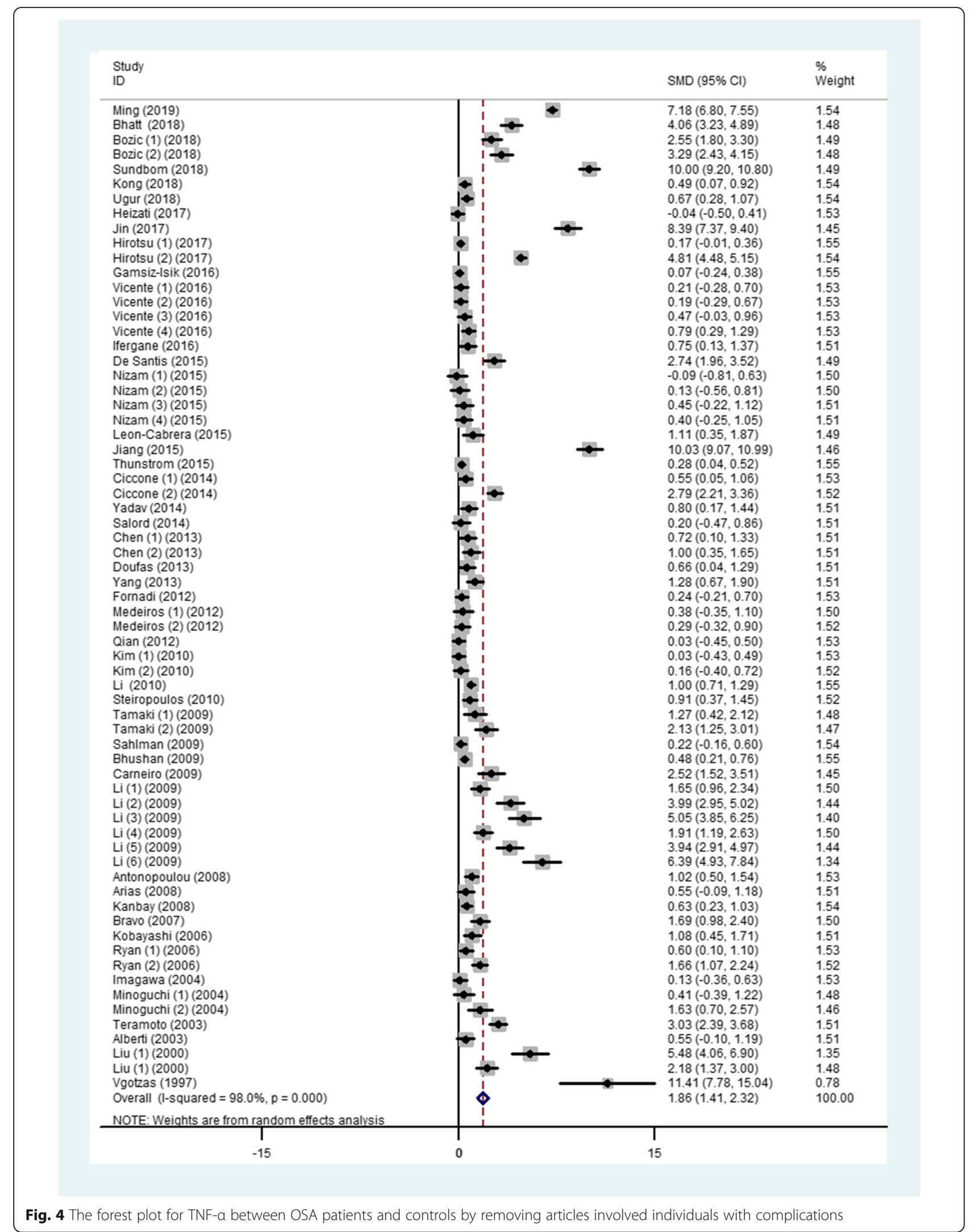




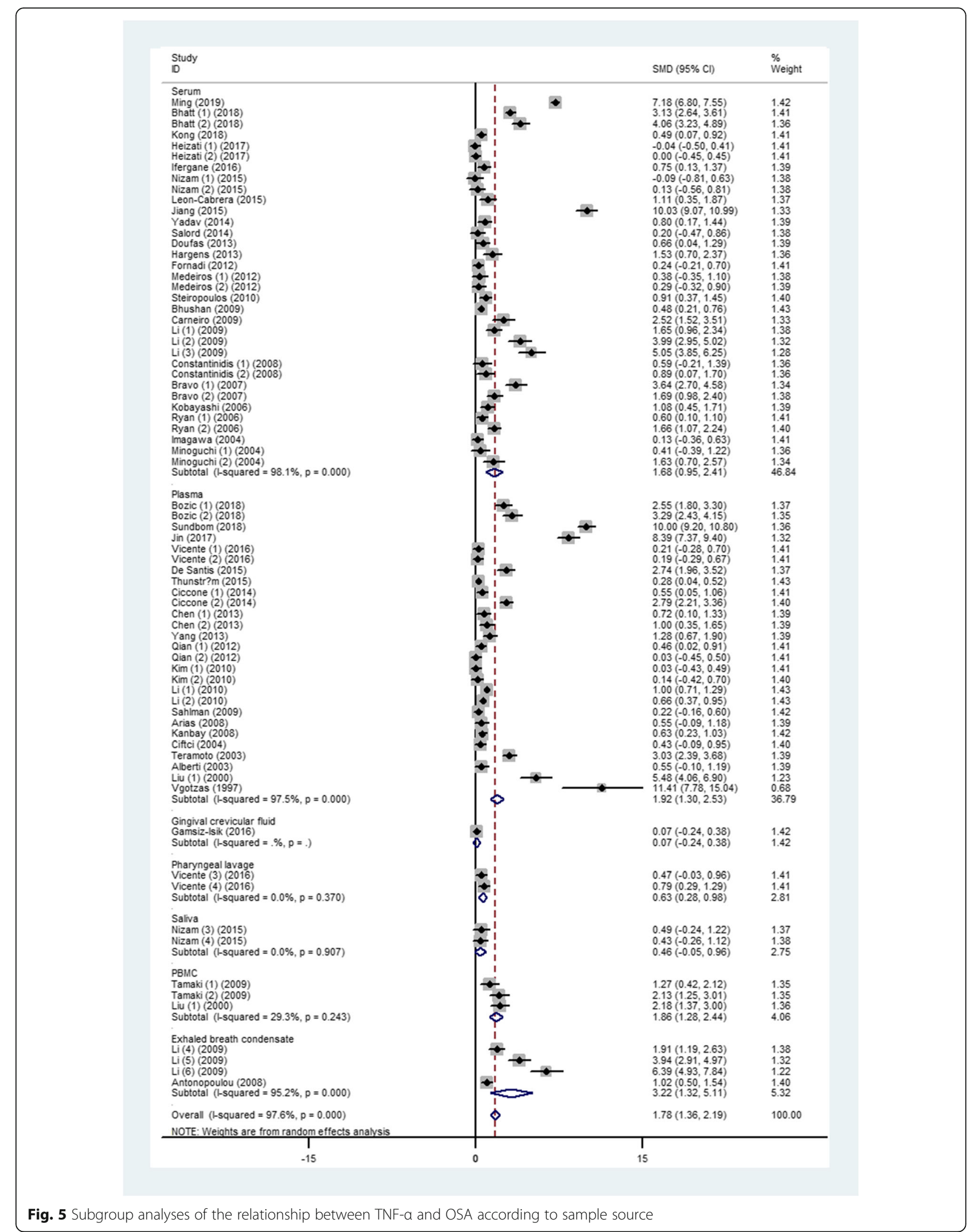




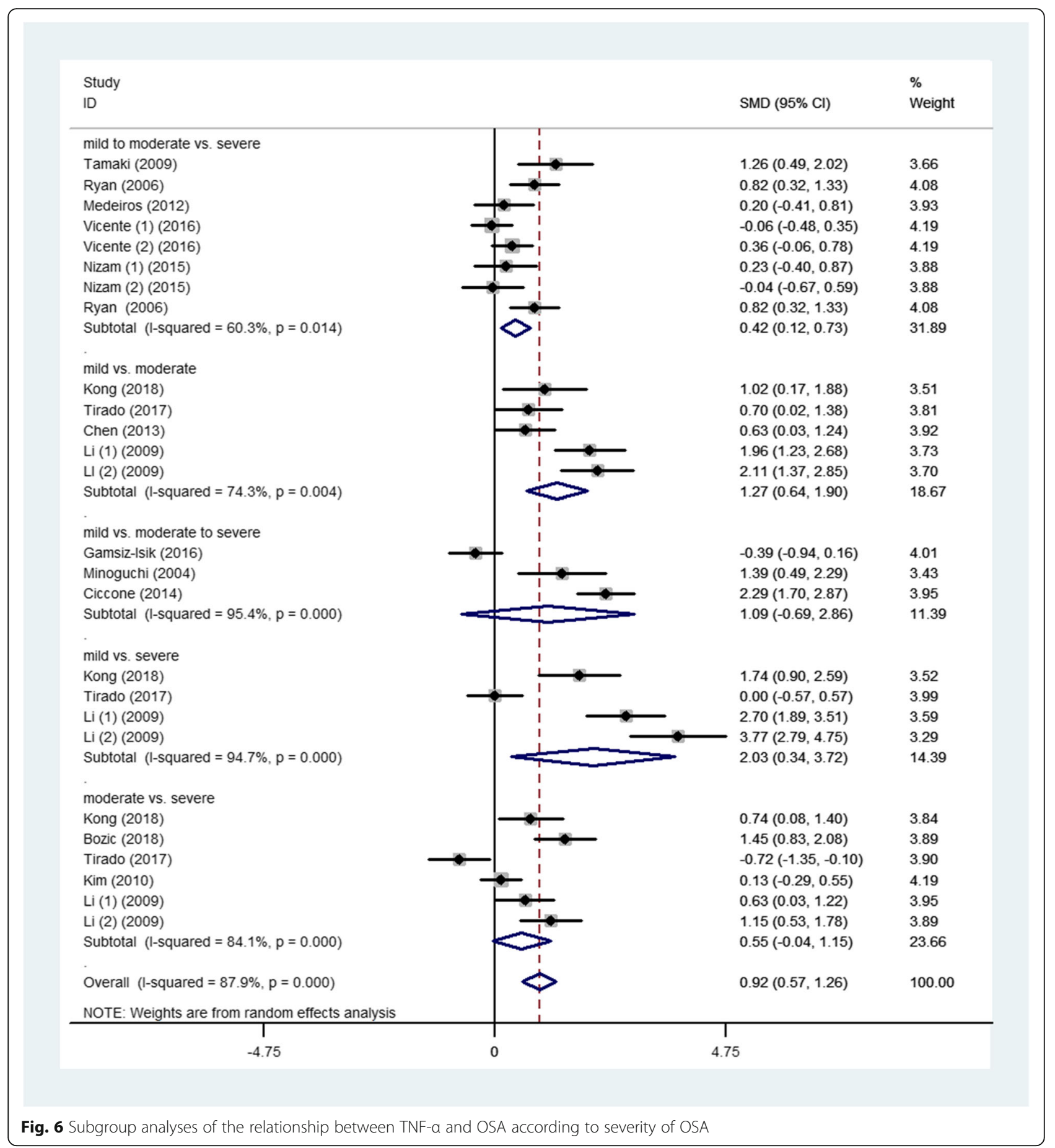

size $(P=0.019)$. None of the other predictors significantly predicted effect size (Table 2 ).

\section{Discussion}

Accumulating evidences has proved that airway inflammation had a close connection to airway collapsibility and anatomic narrowing, which were two vital mechanisms involved in the pathogenesis of OSA. Hypopneas and episodes of breathing cessation during sleep caused an increase in pro-inflammatory serum cytokines, conversely, the risk of infection would aggravate collapse of the airway, which causes a decrement in airflow. During the course of this study, we performed a systematic review and meta-analysis to demonstrate the association of elevated TNF- $\alpha$ with OSA. A total of 50 studies were included in the systematic review and meta-analysis. 
Table 2 Meta-regression analysis coefficients for TNF-a levels

\begin{tabular}{|c|c|c|c|c|c|c|c|}
\hline \multirow{2}{*}{$\begin{array}{l}\text { Covariates } \\
\text { Sample size }\end{array}$} & \multirow{2}{*}{$\begin{array}{l}\text { Elements } \\
-\end{array}$} & \multirow{2}{*}{$\begin{array}{l}\text { Coefficient } \\
0.01095\end{array}$} & \multirow{2}{*}{$\begin{array}{l}\text { Standard Error } \\
0.00551\end{array}$} & \multirow{2}{*}{$\frac{t}{1.99000}$} & \multirow{2}{*}{$\frac{P}{0.05300}$} & \multicolumn{2}{|c|}{ 95\% Confidence Interval } \\
\hline & & & & & & -0.00015 & 0.02205 \\
\hline BMl & - & 0.96000 & 0.34400 & -0.25631 & 0.72067 & 0.96000 & 0.34400 \\
\hline Age & - & 0.79053 & 0.32494 & 2.43000 & 0.01900 & 0.13607 & 1.44500 \\
\hline NOS & - & -0.57894 & 0.30767 & -1.88000 & 0.06600 & -1.19861 & 0.04073 \\
\hline Development & - & -1.83779 & 1.08681 & -1.69000 & 0.09800 & -4.02674 & 0.35115 \\
\hline \multirow[t]{3}{*}{ regions } & America & -1.15015 & 1.41992 & -0.81000 & 0.42200 & -4.01001 & 1.70972 \\
\hline & Asia & -0.18814 & 1.01291 & -0.19000 & 0.85300 & -2.22825 & 1.85196 \\
\hline & Europe & - & - & - & - & - & - \\
\hline \multirow[t]{6}{*}{ Severity } & All & -0.18343 & 1.27352 & -0.14000 & 0.88600 & -2.74843 & 2.38157 \\
\hline & mild & -0.45801 & 1.38464 & -0.33000 & 0.74200 & -3.24681 & 2.33079 \\
\hline & moderate & -0.81363 & 1.51188 & -0.54000 & 0.59300 & -3.85871 & 2.23145 \\
\hline & moderate to severe & -0.20049 & 1.32277 & -0.15000 & 0.88000 & -2.86469 & 2.46371 \\
\hline & severe & -0.29741 & 1.21544 & -0.24000 & 0.80800 & -2.74542 & 2.15061 \\
\hline & mild to moderate & - & - & - & - & - & - \\
\hline \multirow[t]{3}{*}{ Method } & CLIA & 0.21982 & 2.64027 & 0.08000 & 0.93400 & -5.09796 & 5.53759 \\
\hline & ELISA & -3.70431 & 1.97035 & -1.88000 & 0.06700 & -7.67281 & 0.26418 \\
\hline & ECLIA & - & - & - & - & - & - \\
\hline \multirow[t]{7}{*}{ Specimen } & Exhaled breath condensate & 2.90545 & 2.75026 & 1.06000 & 0.29600 & -2.63385 & 8.44475 \\
\hline & PBMC & -3.25580 & 3.41251 & -0.95000 & 0.34500 & -10.12894 & 3.61734 \\
\hline & Pharyngeal lavage & 0.79203 & 2.68878 & 0.29000 & 0.77000 & -4.62345 & 6.20751 \\
\hline & Plasma & -0.27113 & 2.43064 & -0.11000 & 0.91200 & -5.16669 & 4.62444 \\
\hline & Saliva & 0.32275 & 2.90335 & 0.11000 & 0.91200 & -5.52490 & 6.17041 \\
\hline & Serum & 0.60803 & 2.45687 & 0.25000 & 0.80600 & -4.34035 & 5.55641 \\
\hline & Gingival crevicular fluid & - & - & - & - & - & - \\
\hline Gender & - & -0.18789 & 0.35411 & -0.53000 & 0.59800 & -0.90109 & 0.52531 \\
\hline All & - & 9.10716 & 4.37081 & 2.08000 & 0.04300 & 0.30389 & 17.91043 \\
\hline
\end{tabular}

Abbreviations: NOS Newcastle-Ottawa Scale, CLIA chemiluminescence analysis, ECLIA electrochemiluminescence immunoassay, ELISA enzyme linked immunosorbent assay, PBMC peripheral blood mononuclear cell

Patients with OSA had significantly (1.77 times) higher TNF- $\alpha$ levels compared with non-OSA patients $(95 \% \mathrm{CI}$, 1.37 to $\left.2.17, I^{2}=97.8 \%, P<0.0001\right)$. On meta-regression, increasing the mean TNF- $\alpha$ level was associated with increased age in OSA patients (Coefficient [Q]: 0.79, 95\% CI, 0.14-1.45, $P=0.019$ ), and the TNF- $\alpha$ level was consistently correlated with the severity of OSA in the subgroup analysis. TNF- $\alpha$ should be incorporated into a sleep apnea scoring system to stratify the patients for early recognition of severe OSA.

TNF- $\alpha$ possessed a wide range of pro-inflammatory activities and the inappropriate production of TNF was the origin to several diseases, including OSA. In 1997, Vgontzas and colleagues were the first to point that elevated TNF- $\alpha$ was linked to disorders of excessive daytime sleepiness (EDS) $[61,65]$. It illustrated that TNF- $\alpha$ was involved in the regulation of physiological sleep, and increased secretion might be associated with sleepiness and fatigue [65]. Subsequent studies demonstrated that an elevated TNF- $\alpha$ level in OSA was independently of EDS, also, a marker of cardiovascular pathophysiology in OSA [50]. Furthermore, continuous positive airway pressure (CPAP) therapy could suppress the of secretion TNF- $\alpha$, and when OSA patients received anti-TNF- $\alpha$ therapy, significant reduction occurred in daytime sleepiness and AHI $[5,66]$.

Previous meta-analysis studies have evaluated the association between TNF- $\alpha$ levels and OSA, however, they only involved pediatric OSA individuals and less studies were collected $[5,67]$. Infants and juveniles were still in a stage of growth and development, the immune systems and inflammation environments of airway were different from adults. The clinical manifestations, predisposing factors, and polysomnographic data in children with OSA were also different from those in adults. If it was calculated with all-age adults, it definitely affected the credibility and accuracy of the statistical results. Additionally, the units of TNF- $\alpha$ levels were not uniformed, 
and detected methods and specimen were not analyzed, which may cause bring heterogeneity. Consider all of the above, we updated this meta-analysis to remedy the limitations and summarized the connection between the two.

In conjunction with previous research, the current meta-analysis demonstrates that the TNF- $\alpha$ levels were higher in patients with OSA than in healthy controls. By excluding complications such as obesity (over weight), hypertension, and fatty liver disease, the levels were still 1.852 times higher $(P<0.0001)$. Because a substantial heterogeneity existed in the test results, we further performed the subgroup analysis. The results showed the magnitude of the effect was consistent across the subgroups examined, as the coefficients for gender, region and development of countries were significant. As for the female OSA patients, although only 2 studies were added to this analysis, the level of TNF- $\alpha$ was more pronounced than in the male group when compared with healthy individuals $[34,54]$. Women had long been generally underrepresented for OSA, with most sleep research focusing on OSA in males [68]. This gender difference reflected in the menstrual cycle, pregnancy, and menopause, resulting in secretion and fluctuation of sex hormones, therefore, this gender-related regulation participated in mechanisms of sleep disorders [69]. Vgontzas et al. reported that TNF- $\alpha$ was elevated in women with polycystic ovary syndrome, but it was not associated with OSA, unlike in male [70]. Further insightful studies should be devoted to the pathophysiology of females with OSA to identify the mechanism of this gender difference.

Obesity is regarded as a chronic low-grade inflammatory state. Obesity had been shown to have an effect on pulmonary functions, affecting the residual volume and total lung capacity, and was considered to be a risk factor of OSA [71]. Considering the possible mechanism, TNF- $\alpha$ is one of the key proinflammatory cytokines. In the inflammatory condition, hypoxia of adipocytes is related to macrophage infiltration, which is the most abundant type of immune cell in adipose tissue. Together with macrophages, adipocytes release various biologically active molecules to affect the innate and adaptive immune system, such as cytokines, chemokines, complement proteins, and other acute-phase proteins (also known as adipokines). These secretions further contributed to maintain the activation of immune cells and their infiltration into regulatory organs [72]. Based on a number of laboratory data and clinical evidence, TNF- $\alpha$ inhibitors were implied as new therapeutic strategies in several immune-related diseases, including rheumatoid arthritis, asthma, sarcoidosis, inflammatory bowel disease, pancreatitis, and so on [73-75].
Studies had investigated the effects of weight loss on measures of airway inflammation [76]. In this metaanalysis, we analyzed related confounding factors through meta regression, however, BMI did not reach statistical significance. Meanwhile, obesity is also associated with increased numbers of adipose tissue macrophages. Especially in the visceral adipose tissue depot, an increasing number of adipose tissue macrophages were showing even more in the presence of abdominal obesity. And, along with weight reduction, a decrease in adipose tissue macrophages numbers can be observed [77]. The prevalence of obesity and inflammatory also raises steadily among older age groups, especially a fat deposition in abdominal obesity, a major contributor to the metabolic syndrome and age-related disease, rather than subcutaneous fat. Moreover, aging is associated with higher levels of pro-inflammatory cytokines. The fat mass redistribution and increased fat mass accumulation with age lead to disregulation of cytokines and adipokine secretion which linked to key features of local and systemic inflammation, such as TNF- $\alpha$. Increasing the incidence of obesity among the elderly may probably intensify and accelerate the problem of age-related inflammation processes [78]. Considering the close relationships among age, obesity, and immune balances, we preferred to believe the immune intervening method, taking TNF- $\alpha$ inhibitors as the typical example, would provide new insight into the treatment of OSA.

Past studies had demonstrated that proinflammatory cytokines were consistently correlated with severity of OSA [42, 44]. This phenomenon was also shown in TNF- $\alpha$ in the current study. The specimen source used for measurement of TNF- $\alpha$ was seldom discussed, and most of the previous studies used peripheral blood. Exhaled breath condensate (EBC) is a non-invasive and safe method to monitor inflammation, and it has already been used to measure biomarkers of inflammation in several respiratory diseases, such as asthma and chronic obstructive disease [44]. Some research has validated that it could be a biomarkers to predict OSA. Using a subgroup analysis, TNF- $\alpha$ levels in EBC had equal effectiveness as in blood specimens, which may suggest its value in predicting severity of OSA by EBC.

Because of the heterogeneity in this meta-analysis, we performed a meta-regression, and the results showed age was significant associated with the effects estimate. Because all the OSA patients were adults, there was still a large span in age in our meta-analysis. The prevalence of OSA tended to increase with age, whereas, the clinical severity was reversed in available studies [79-81]. The speculative explanations may be attributed to influence of BMI on the severity of OSA, and the high collapsibility of the upper airways in the elderly. Additionally, the inclusion criteria varied among each other; hence some 
unavoidable complications could have been introduced into the study samples.

In this study, we tried to eliminate utmost confounding factors to draw a reliable conclusion. However, there were still several limitations that should be addressed. First, because of the number of studies that we analyzed, publishing bias inevitably existed. Even though we had contacted with the authors for additional details regarding the studies, data were still unavailable from the literatures. Second, the inflammation fluctuated in $1 \mathrm{~d}$; additionally, the times of drawing blood were not stable, which meant TNF- $\alpha$ levels were not measured on the same baseline, for which a difference occurred throughout the study population. Third, diet, lifestyles, environmental factors, etc., all related to the state of OSA, in turn, affecting the secretion of inflammatory factors in the body.

\section{Conclusion}

In conclusion, this meta-analysis identified a significant association between OSA and elevated TNF- $\alpha$ level in adults and was consistently correlated with severity of OSA. Although the above findings need to be confirmed in larger case-control cohorts, they guides the way to seeking a potential biomarker and therapeutic target in adults with OSA. Further studies are needed to better standardized detection of inflammatory cytokines (TNF$\alpha)$ and establish an exact link to the assessment of OSA.

\section{Supplementary information}

Supplementary information accompanies this paper at https://doi.org/10. 1186/s12890-020-01253-0.

\footnotetext{
Additional file 1: Table S1. Sensitivity analysis by omitting each of the included literatures.

Additional file 2: Figure S1. Sensitivity analysis.

Additional file 3: Figure S2. Subgroup analyses of the relationship between TNF-a and OSA according to development of country.

Additional file 4: Figure S3. Subgroup analyses of the relationship between TNF-a and OSA according to continent.

Additional file 5: Figure S4. Subgroup analyses of the relationship between TNF- $a$ and OSA according to gender.

Additional file 6: Figure S5. Subgroup analyses of the relationship between TNF-a and OSA according to laboratory examination.
}

\footnotetext{
Abbreviations

AHI: Apnea-hypopnea index; BMl: Body mass index; CPAP: Continuous positive airway pressure; CLIA: Chemiluminescence analysis; EBC: Exhaled breath condensate; EDS: Excessive daytime sleepiness;

ECLIA: Electrochemiluminescence immunoassay; ELISA: Enzyme linked immunosorbent assay; GCF: Gingival crevicular fluid; NAFLD: Non-alcoholic fatty liver disease; NOS: Newcastle-Ottawa Scale; NR: Not record;

OSA: Obstructive sleep apnea; PBMC : Peripheral blood mononuclear cell; PHAL: Pharyngeal lavage; PICOS: Population, intervention, comparison, outcomes, and study design; SMD: Standard mean difference; TNF-a: Tumor necrosis factor-a
}

\section{Acknowledgements}

Not applicable.

\section{Authors' contributions}

YC analysed and interpreted the patient data and was a major contributor to the writing of the manuscript. YS and PN contributed to the acquisition and analysis. LZ, JQ, and SW contributed to the literature search and analysis. QL contributed to the conception and design of the work. All co-authors contributed to the study design, revised the manuscript and approved the final manuscript.

\section{Funding}

This work was supported by Natural Science Basic Research Plan in Shaanxi Province of China (Program No.2020JQ-543; 2020JQ-927); Fundamental Research Funds for the Central Universities under Grant xzy012019129; Xi'an Science and Technology program SF1510(4); Xi'an Science and Technology program under Grant J20170219ll; and the Natural Science Foundation of Sichuan Province (2019YJ0067). The funding bodies played no role in the design of the study and collection, analysis, and interpretation of data and in writing the manuscript.

\section{Availability of data and materials}

All data and material in this paper could achieve in supplemental materials.

Ethics approval and consent to participate

Not applicable.

\section{Consent for publication}

Not applicable.

\section{Competing interests}

The authors declare that there is no conflict of interests regarding the publication of this paper.

\section{Author details}

${ }^{1}$ Department of Pulmonary and Critical Care Medicine, The Second Affiliated Hospital of Xi'an Jiaotong University (Xibei Hospital), Xi'an, Shaanxi, China. ${ }^{2}$ Department of Laboratory Medicine, West China Hospital, Sichuan University, Chengdu, Sichuan, China. ${ }^{3}$ Institute of Pediatric Diseases, The Affiliated Children Hospital of Xi'an Jiaotong University, Xi'an, Shaanxi, China. ${ }^{4}$ Clinical Laboratory, The Affiliated Children Hospital of Xi'an Jiaotong University, Xi'an, Shaanxi, China. ${ }^{5}$ Department of Ultrasound, School of Medicine, The Second Affiliated Hospital of Zhejiang University, Zhejiang, Hangzhou, China.

Received: 28 December 2019 Accepted: 5 August 2020

Published online: 12 August 2020

\section{References}

1. Gottlieb DJ, Punjabi NM. Diagnosis and Management of Obstructive Sleep Apnea: a review. JAMA. 2020;323(14):1389-400.

2. Young T, Palta M, Dempsey J, Skatrud J, Weber S, Badr S. The occurrence of sleep-disordered breathing among middle-aged adults. N Engl J Med. 1993; 328(17):1230-5.

3. Cao Y, Wu S, Zhang L, Yang Y, Cao S, Li Q. Association of allergic rhinitis with obstructive sleep apnea: a meta-analysis. Medicine. 2018;97(51):e13783.

4. MacKenzie S, Planas JV, Goetz FW. LPS-stimulated expression of a tumor necrosis factor-alpha mRNA in primary trout monocytes and in vitro differentiated macrophages. Dev Comp Immunol. 2003;27(5):393-400.

5. Nadeem R, Molnar J, Madbouly EM, Nida M, Aggarwal S, Sajid H, Naseem J, Loomba R. Serum inflammatory markers in obstructive sleep apnea: a metaanalysis. J Clin Sleep Med. 2013;9(10):1003-12

6. Kheirandish-Gozal L, Gozal D. Obstructive sleep apnea and inflammation: proof of concept based on two illustrative cytokines. Int J Mol Sci. 2019; 20(3):459.

7. Krueger JM, Obál FJ, Fang J, Kubota T, Taishi P. The role of cytokines in physiological sleep regulation. Ann N Y Acad Sci. 2001;933:211-21.

8. He K, Kapur VK. Sleep-disordered breathing and excessive daytime sleepiness. Sleep Med Clin. 2017;12(3):369-82.

9. Walsh JA, Duffin KC, Crim J, Clegg DO. Lower frequency of obstructive sleep apnea in spondyloarthritis patients taking TNF-inhibitors. J Clin Sleep Med. 2012;8(6):643-8.

10. Minoguchi K, Tazaki T, Yokoe T, Minoguchi H, Watanabe $Y$, Yamamoto M, Adachi M. Elevated production of tumor necrosis factor-alpha by 
monocytes in patients with obstructive sleep apnea syndrome. Chest. 2004; 126(5):1473-9.

11. Ming H, Tian A, Liu B, Hu Y, Liu C, Chen R, Cheng L. Inflammatory cytokines tumor necrosis factor-alpha, interleukin-8 and sleep monitoring in patients with obstructive sleep apnea syndrome. Exp Ther Med. 2019;17(3):1766-70.

12. Epstein LJ, Kristo D, Strollo PJ Jr, Friedman N, Malhotra A, Patil SP, Ramar K, Rogers R, Schwab RJ, Weaver EM, et al. Clinical guideline for the evaluation, management and long-term care of obstructive sleep apnea in adults. J Clin Sleep Med. 2009;5(3):263-76.

13. Wan X, Wang W, Liu J, Tong T. Estimating the sample mean and standard deviation from the sample size, median, range and/or interquartile range. BMC Med Res Methodol. 2014;14(1):135.

14. Hozo SP, Djulbegovic B, Hozo I. Estimating the mean and variance from the median, range, and the size of a sample. BMC Med Res Methodol. 2005;5(1):13.

15. DerSimonian R, Laird N. Meta-analysis in clinical trials revisited. Contemp Clin Trials. 2015;45(Pt A):139-45

16. Alberti A, Sarchielli P, Gallinella E, Floridi A, Floridi A, Mazzotta G, Gallai V. Plasma cytokine levels in patients with obstructive sleep apnea syndrome: a preliminary study. J Sleep Res. 2003;12(4):305-11.

17. Antonopoulou S, Loukides S, Papatheodorou G, Roussos C, Alchanatis M. Airway inflammation in obstructive sleep apnea: is leptin the missing link? Respir Med. 2008;102(10):1399-405.

18. Arias MA, Garcia-Rio F, Alonso-Fernandez A, Hernanz A, Hidalgo R, MartinezMateo V, Bartolome S, Rodriguez-Padial L. CPAP decreases plasma levels of soluble tumour necrosis factor-alpha receptor 1 in obstructive sleep apnoea. Eur Respir J. 2008;32(4):1009-15.

19. Bhatt SP, Guleria R, Vikram NK, Gupta AK. Non-alcoholic fatty liver disease is an independent risk factor for inflammation in obstructive sleep apnea syndrome in obese Asian Indians. Sleep Breathing. 2019;23(1):171-8.

20. Bhushan B, Guleria R, Misra A, Luthra K, Vikram NK. TNF-alpha gene polymorphism and TNF-alpha levels in obese Asian Indians with obstructive sleep apnea. Respir Med. 2009;103(3):386-92.

21. Bozic J, Borovac JA, Galic T, Kurir TT, Supe-Domic D, Dogas Z. Adropin and inflammation biomarker levels in male patients with obstructive sleep apnea: a link with glucose metabolism and sleep parameters. J Clin Sleep Med. 2018;14(7):1109-18.

22. Bravo Mde L, Serpero LD, Barcelo A, Barbe F, Agusti A, Gozal D. Inflammatory proteins in patients with obstructive sleep apnea with and without daytime sleepiness. Sleep Breathing. 2007;11(3):177-85.

23. Carneiro G, Togeiro SM, Ribeiro-Filho FF, Truksinas E, Ribeiro AB, Zanella MT, Tufik S. Continuous positive airway pressure therapy improves hypoadiponectinemia in severe obese men with obstructive sleep apnea without changes in insulin resistance. Metab Syndr Relat Disord. 2009;7(6): 537-42.

24. Chen PC, Guo CH, Tseng CJ, Wang KC, Liu PJ. Blood trace minerals concentrations and oxidative stress in patients with obstructive sleep apnea. J Nutr Health Aging. 2013;17(8):639-44.

25. Ciccone MM, Scicchitano P, Zito A, Cortese F, Boninfante B, Falcone VA, Quaranta VN, Ventura VA, Zucano A, Di Serio F, et al. Correlation between inflammatory markers of atherosclerosis and carotid intima-media thickness in Obstructive Sleep Apnea. Molecules (Basel, Switzerland). 2014;19(2):1651-62.

26. Ciftci TU, Kokturk O, Bukan N, Bilgihan A. The relationship between serum cytokine levels with obesity and obstructive sleep apnea syndrome. Cytokine. 2004;28(2):87-91.

27. Constantinidis J, Ereliadis S, Angouridakis N, Konstantinidis I, Vital V, Angouridaki C. Cytokine changes after surgical treatment of obstructive sleep apnoea syndrome. Eur Arch Oto-Rhino-Laryngol. 2008;265(10):1275-9.

28. De Santis S, Cambi J, Tatti P, Bellussi L, Passali D. Changes in ghrelin, leptin and pro-inflammatory cytokines after therapy in Obstructive Sleep Apnea Syndrome (OSAS) patients. Otolaryngol Polska. 2015;69(2):1-8.

29. Doufas AG, Tian L, Padrez KA, Suwanprathes P, Cardell JA, Maecker HT, Panousis P. Experimental pain and opioid analgesia in volunteers at high risk for obstructive sleep apnea. PLoS One. 2013;8(1):e54807.

30. Fornadi K, Lindner A, Czira ME, Szentkiralyi A, Lazar AS, Zoller R, Turanyi CZ, Veber O, Novak M, Mucsi I, et al. Lack of association between objectively assessed sleep disorders and inflammatory markers among kidney transplant recipients. Int Urol Nephrol. 2012;44(2):607-17.

31. Gamsiz-Isik H, Kiyan E, Bingol Z, Baser U, Ademoglu E, Yalcin F. Does obstructive sleep apnea increase the risk for periodontal disease? A casecontrol study. J Periodontol. 2017;88(5):443-9.
32. Hargens TA, Guill SG, Kaleth AS, Nickols-Richardson SM, Miller LE, Zedalis D, Gregg JM, Gwazdauskas F, Herbert WG. Insulin resistance and adiposederived hormones in young men with untreated obstructive sleep apnea. Sleep Breathing. 2013;17(1):403-9.

33. Heizati M, Li N, Shao L, Yao X, Wang Y, Hong J, Zhou L, Zhang D, Chang G, Abulikemu S. Does increased serum d-lactate mean subclinical hyperpermeability of intestinal barrier in middle-aged nonobese males with OSA? Medicine. 2017:96(49):e9144.

34. Hirotsu C, Albuquerque RG, Nogueira H, Hachul H, Bittencourt L, Tufik S, Andersen ML. The relationship between sleep apnea, metabolic dysfunction and inflammation: the gender influence. Brain Behav Immun. 2017;59:211-8.

35. Ifergane G, Ovanyan A, Toledano R, Goldbart A, Abu-Salame I, Tal A, Stavsky $M$, Novack V. Obstructive sleep apnea in acute stroke: a role for systemic inflammation. Stroke. 2016;47(5):1207-12.

36. Imagawa S, Yamaguchi Y, Ogawa K, Obara N, Suzuki N, Yamamoto M, Nagasawa T. Interleukin-6 and tumor necrosis factor-alpha in patients with obstructive sleep apnea-hypopnea syndrome. Respiration. 2004;71(1):24-9.

37. Jiang $\mathrm{H}, \mathrm{Cao} H$, Wang $P$, Liu W, Cao F, Chen J. Tumour necrosis factoralpha/interleukin-10 ratio in patients with obstructive sleep apnoea hypopnoea syndrome. J Laryngol Otol. 2015;129(1):73-8.

38. Jin F, Liu J, Zhang X, Cai W, Zhang Y, Zhang W, Yang J, Lu G, Zhang X. Effect of continuous positive airway pressure therapy on inflammatory cytokines and atherosclerosis in patients with obstructive sleep apnea syndrome. Mol Med Rep. 2017;16(5):6334-9.

39. Kanbay A, Kokturk O, Ciftci TU, Tavil Y, Bukan N. Comparison of serum adiponectin and tumor necrosis factor-alpha levels between patients with and without obstructive sleep apnea syndrome. Respiration. 2008;76(3):324-30.

40. Kim J, Lee CH, Park CS, Kim BG, Kim SW, Cho JH. Plasma levels of MCP-1 and adiponectin in obstructive sleep apnea syndrome. Arch Otolaryngol. 2010;136(9):896-9.

41. Kobayashi K, Nishimura Y, Shimada T, Yoshimura S, Funada Y, Satouchi M, Yokoyama M. Effect of continuous positive airway pressure on soluble CD40 ligand in patients with obstructive sleep apnea syndrome. Chest. 2006; 129(3):632-7.

42. Kong Y, Li Z, Tang T, Wu H, Liu J, Gu L, Zhao T, Huang Q. The level of lipopolysaccharide-binding protein is elevated in adult patients with obstructive sleep apnea. BMC Pulm Med. 2018;18(1):90.

43. Leon-Cabrera S, Arana-Lechuga Y, Esqueda-Leon E, Teran-Perez G, GonzalezChavez A, Escobedo G, Velazquez Moctezuma J. Reduced systemic levels of IL-10 are associated with the severity of obstructive sleep apnea and insulin resistance in morbidly obese humans. Mediat Inflamm. 2015;2015:493409.

44. Li Y, Chongsuvivatwong V, Geater A, Liu A. Exhaled breath condensate cytokine level as a diagnostic tool for obstructive sleep apnea syndrome. Sleep Med. 2009;10(1):95-103.

45. Li NF, Yao XG, Zhu J, Yang J, Liu KJ, Wang YC, Wang XL, Zu FY. Higher levels of plasma TNF-alpha and neuropeptide $Y$ in hypertensive patients with obstructive sleep apnea syndrome. Clin Exp Hypertension. 2010;32(1):54-60.

46. Liu H, Liu J, Xiong S, Shen G, Zhang Z, Xu Y. The change of interleukin-6 and tumor necrosis factor in patients with obstructive sleep apnea syndrome. J Tongji Med Univ. 2000;20(3):200-2.

47. Medeiros CA, de Bruin VM, Andrade GM, Coutinho WM, de Castro-Silva C, de Bruin PF. Obstructive sleep apnea and biomarkers of inflammation in ischemic stroke. Acta Neurol Scand. 2012;126(1):17-22.

48. Nizam N, Basoglu OK, Tasbakan MS, Lappin DF, Buduneli N. Is there an association between obstructive sleep apnea syndrome and periodontal inflammation? Clin Oral Investig. 2016;20(4):659-68.

49. Qian X, Yin T, Li T, Kang C, Guo R, Sun B, Liu C. High levels of inflammation and insulin resistance in obstructive sleep apnea patients with hypertension. Inflammation. 2012;35(4):1507-11.

50. Ryan S, Taylor CT, McNicholas WT. Predictors of elevated nuclear factorkappaB-dependent genes in obstructive sleep apnea syndrome. Am J Respir Crit Care Med. 2006;174(7):824-30.

51. Sahlman J, Miettinen K, Peuhkurinen K, Seppa J, Peltonen M, Herder C, Punnonen K, Vanninen E, Gylling H, Partinen M, et al. The activation of the inflammatory cytokines in overweight patients with mild obstructive sleep apnoea. J Sleep Res. 2010;19(2):341-8.

52. Salord N, Gasa M, Mayos M, Fortuna-Gutierrez AM, Montserrat JM, Sanchezde-la-Torre M, Barcelo A, Barbe F, Vilarrasa N, Monasterio C. Impact of OSA on biological markers in morbid obesity and metabolic syndrome. J Clin Sleep Med. 2014;10(3):263-70. 
53. Steiropoulos P, Papanas N, Nena E, Antoniadou M, Serasli E, Papoti S, Hatzizisi O, Kyriazis G, Tzouvelekis A, Maltezos E et al: Inflammatory markers in middle-aged obese subjects: does obstructive sleep apnea syndrome play a role? Mediat Inflamm 2010, 2010:675320.

54. Sundbom F, Janson C, Malinovschi A, Lindberg E. Effects of coexisting asthma and obstructive sleep apnea on sleep architecture, oxygen saturation, and systemic inflammation in women. J Clin Sleep Med. 2018; 14(2):253-9.

55. Tamaki S, Yamauchi M, Fukuoka A, Makinodan K, Koyama N, Tomoda K, Yoshikawa M, Kimura H. Production of inflammatory mediators by monocytes in patients with obstructive sleep apnea syndrome. Internal Med (Tokyo, Japan). 2009;48(15):1255-62.

56. Teramoto $\mathrm{S}$, Yamamoto $\mathrm{H}$, Ouchi $\mathrm{Y}$ : Increased $\mathrm{C}$-reactive protein and increased plasma interleukin-6 may synergistically affect the progression of coronary atherosclerosis in obstructive sleep apnea syndrome. Circulation 2003, 107(5):E40-40.

57. Thomopoulos C, Tsioufis C, Dimitriadis K, Tsiachris D, Tousoulis D, Manolis A, Alchanatis M, Kallikazaros I, Stefanadis C. Obstructive sleep apnoea syndrome is associated with enhanced sub-clinical inflammation and asymmetric dimethyl-arginine levels in hypertensives. J Hum Hypertens. 2009;23(1):65-7.

58. Thunstrom E, Glantz H, Fu M, Yucel-Lindberg T, Petzold M, Lindberg K, Peker $Y$. Increased inflammatory activity in nonobese patients with coronary artery disease and obstructive sleep apnea. Sleep. 2015;38(3):463-71.

59. Tirado R, Masdeu MJ, Vigil L, Rigla M, Luna A, Rebasa P, Pareja R, Hurtado M, Caixas A. Impact of bariatric surgery on Heme Oxygenase-1, inflammation, and insulin resistance in morbid obesity with obstructive sleep apnea. Obes Surg. 2017;27(9):2338-46.

60. Ugur KS, Acar M, Ozol D, Dagli E, Oznur M, Kosus A, Gunduz M. Gene expression profiles of tumor necrosis factor-alpha and Endothelin-1 in obstructive sleep apnea. ORL J Otorhinolaryngol Relat Spec. 2019;81(1):16-23.

61. Vgontzas AN, Papanicolaou DA, Bixler EO, Kales A, Tyson K, Chrousos GP. Elevation of plasma cytokines in disorders of excessive daytime sleepiness: role of sleep disturbance and obesity. J Clin Endocrinol Metab. 1997;82(5): 1313-6.

62. Vicente E, Marin JM, Carrizo SJ, Osuna CS, Gonzalez R, Marin-Oto M, Forner M, Vicente P, Cubero P, Gil AV, et al. Upper airway and systemic inflammation in obstructive sleep apnoea. Eur Respir J. 2016;48(4):1108-17.

63. Yadav R, France M, Aghamohammadzadeh R, Liu Y, Hama S, Kwok S, Schofield J, Turkington P, Syed AA, Malik R, et al. Impairment of highdensity lipoprotein resistance to lipid peroxidation and adipose tissue inflammation in obesity complicated by obstructive sleep apnea. J Clin Endocrinol Metab. 2014;99(9):3390-8.

64. Yang D, Liu Z, Luo Q. Plasma ghrelin and pro-inflammatory markers in patients with obstructive sleep apnea and stable coronary heart disease. Med Sci Monitor. 2013;19:251-6.

65. Vgontzas AN, Bixler EO, Chrousos GP. Sleep apnea is a manifestation of the metabolic syndrome. Sleep Med Rev. 2005;9(3):211-24.

66. Vgontzas AN, Zoumakis E, Lin HM, Bixler EO, Trakada G, Chrousos GP. Marked decrease in sleepiness in patients with sleep apnea by etanercept, a tumor necrosis factor-alpha antagonist. J Clin Endocrinol Metab. 2004;89(9): 4409-13.

67. Li Q, Zheng X. Tumor necrosis factor alpha is a promising circulating biomarker for the development of obstructive sleep apnea syndrome: a meta-analysis. Oncotarget. 2017;8(16):27616-26.

68. Driver H, Cachon J, Dableh L, Cushing M, Baker F, Cote K, Wolfson A. Gender representation in sleep research. J Sleep Res. 1999:8(2):157-9.

69. Paul KN, Turek FW, Kryger MH. Influence of sex on sleep regulatory mechanisms. J Women's Health. 2008;17(7):1201-8.

70. Vgontzas AN, Trakada G, Bixler EO, Lin HM, Pejovic S, Zoumakis E, Chrousos GP, Legro RS. Plasma interleukin 6 levels are elevated in polycystic ovary syndrome independently of obesity or sleep apnea. Metab Clin Exp. 2006; 55(8):1076-82.

71. Fantuzzi G. Adipose tissue, adipokines, and inflammation. J Allergy Clin Immunol. 2005;115(5):911-9 quiz 920.

72. Huh JY, Park YJ, Ham M, Kim JB. Crosstalk between adipocytes and immune cells in adipose tissue inflammation and metabolic dysregulation in obesity. Mol Cells. 2014;37(5):365-71.

73. Udalova I, Monaco C, Nanchahal J, Feldmann M. Anti-TNF Therapy. Microbiol Spectrum. 2016:4(4).
74. Malaviya R, Laskin JD, Laskin DL. Anti-TNFa therapy in inflammatory lung diseases. Pharmacol Ther. 2017;180:90-8.

75. Radner H, Aletaha D. Anti-TNF in rheumatoid arthritis: an overview. Wiener Med Wochenschrift (1946). 2015;165(1-2):3-9.

76. Maurizi G, Della Guardia L, Maurizi A, Poloni A. Adipocytes properties and crosstalk with immune system in obesity-related inflammation. J Cell Physiol. 2018;233(1):88-97.

77. Lee BC, Lee J. Cellular and molecular players in adipose tissue inflammation in the development of obesity-induced insulin resistance. Biochim Biophys Acta. 2014;1842(3):446-62.

78. Jura M, Kozak LP. Obesity and related consequences to ageing. Age (Dordrecht, Netherlands). 2016;38(1):23.

79. Gabbay IE, Lavie P. Age- and gender-related characteristics of obstructive sleep apnea. Sleep Breathing. 2012;16(2):453-60.

80. Bixler EO, Vgontzas AN, Ten Have T, Tyson K, Kales A. Effects of age on sleep apnea in men: I. prevalence and severity. Am J Respir Crit Care Med. 1998; 157(1):144-8.

81. Chung S, Yoon IY, Lee CH, Kim JW. Effects of age on the clinical features of men with obstructive sleep apnea syndrome. Respiration. 2009:78(1):23-9.

\section{Publisher's Note}

Springer Nature remains neutral with regard to jurisdictional claims in published maps and institutional affiliations.
Ready to submit your research? Choose BMC and benefit from:

- fast, convenient online submission

- thorough peer review by experienced researchers in your field

- rapid publication on acceptance

- support for research data, including large and complex data types

- gold Open Access which fosters wider collaboration and increased citations

- maximum visibility for your research: over $100 \mathrm{M}$ website views per year

At BMC, research is always in progress.

Learn more biomedcentral.com/submissions 